\title{
CYP1A2 polymorphism in Chinese patients with acute liver injury induced by Polygonum multiflorum
}

\author{
K.F. Ma, X.G. Zhang and H.Y. Jia \\ The First Affiliated Hospital, Zhejiang University, Hangzhou, China \\ Corresponding author: H.Y. Jia \\ E-mail: jancemkf@163.com \\ Genet. Mol. Res. 13 (3): 5637-5643 (2014) \\ Received November 5, 2013 \\ Accepted February 10, 2014 \\ Published July 25, 2014 \\ DOI http://dx.doi.org/10.4238/2014.July.25.19
}

\begin{abstract}
The objective of this study was to evaluate the genotype and allelic frequencies of CYP1A2 in Chinese patients with acute liver injury induced by Polygonum multiflorum. We examined the clinical mechanism of acute liver injury induced by $P$. multiflorum. According to the diagnostic criteria for drug-induced liver injury (DILI), 43 cases of $P$. multiflorum-induced liver injury admitted to the First Affiliated Hospital, Zhejiang University were identified between January 2008 and December 2012. An additional 43 control subjects were also chosen. Several alleles, including $* 1 \mathrm{C}, * 1 \mathrm{~F}, * 2, * 7, * 9$, and $* 11$ of $C Y P 1 A 2$ were amplified from genomic DNA and sequenced. We used the chi-square test to determine whether CYP1A2 allele polymorphisms are associated with acute liver injury induced by $P$. multiflorum. The frequency of the CYP $1 A 2 * 1$ C allele was $46.5 \%$ in P. multiflorum-induced DILI patients, which was significantly different from the frequency of $27.9 \%$ observed in healthy subjects. The frequency of the $C Y P 1 A 2 * 1 \mathrm{~F}$ allele was $63.9 \%$ in P. multiflorum-induced DILI patients, compared to $57.0 \%$ in healthy controls; the difference was not significant. The allelic frequencies of CYP1A2*2, CYP1A2*7, CYP1A2*9, and CYP1A2*11 were too low to be detected. The frequency of the $C Y P 1 A 2 * 1 \mathrm{C}$ mutation in Chinese
\end{abstract}


patients with $P$. multiflorum-induced acute liver injury differed from that in healthy Chinese people, indicating that $C Y P 1 A 2 * 1 \mathrm{C}$ is probably related to metabolism of $P$. multiflorum, which is followed by acute liver injury.

Key words: CYP1A2; Drug-induced liver injury; Gene polymorphism; Polygonum multiflorum

\section{INTRODUCTION}

Reports of adverse reactions induced by traditional Chinese medicines (TCM) have increased (Ko, 2004). Polygonum multiflorum is one form of TCM, and is sold as a food supplement to improve immune function and enhance hair growth through its antioxidant properties (Wong et al., 2006). However, adverse reactions induced by P. multiflorum are common, with patients developing drug-induced liver injury (DILI) and even liver failure (Mazzanti et al., 2004; Panis et al., 2005; Cárdenas et al., 2006; Jung et al., 2011). Although the mechanism is unknown, many studies have suggested that an idiosyncratic reaction occurs, which is related to genetic polymorphisms in various enzymes (Empey, 2010).

Genetic variation in cytochrome P450 (CYP450) is known to contribute to inter-individual variation in drug metabolism and response to medication (Polimanti et al., 2012). For example, CYP450 1A2 gene polymorphisms are thought to be involved in the metabolism of theophylline; a study by Uslu et al. (2010) suggested that genetic alterations in CYP1A2 play a role both in the pharmacogenetics of theophylline and in the development of chronic obstructive pulmonary disorder. Gervasini et al. (2012) found that the CYP $3 A 4 * 1 \mathrm{~B}-C Y P 3 A 5 * 1$ haplotype may have a profound impact on tacrolimus pharmacokinetics, which may be related to the occurrence of toxicity or acute rejection in renal transplant recipients treated with tacrolimus.

Among CYP enzymes, CYP1A2 is prominently involved in the biotransformation of emodin, which is the putative component contributing to P. multiflorum-induced liver injury (Zhang et al., 2010). Some CYP1A2 gene variants have been reported to be responsible for altered activity of the $C Y P 1 A 2$ gene. While $C Y P 1 A 2 * 1 \mathrm{~F}$ has been associated with increased activity, CYP1A2*1C, CYP1A2*1K, CYP1A2*3,CYP1A2*4, CYP1A2*6, CYP1A2*7, $C Y P 1 A 2 * 8, C Y P 1 A 2 * 11, C Y P 1 A 2 * 15$, and $C Y P 1 A 2 * 16$ variants have been associated with decreased CYPIA2 gene activity (Soyama et al., 2005; Anonymous, 2013). However, no studies have examined CYP1A2 gene polymorphisms in acute liver injury induced by $P$. multiflorum. In this study, we examined the clinical causes of acute liver injury induced by $P$. multiflorum.

\section{MATERIAL AND METHODS}

\section{Subjects and case recruitment}

Data from 355 DILI patients admitted to the First Affiliated Hospital, Zhejiang University between January 2008 and December 2012 were collected. Diagnoses were established using the Maria criteria scale, which is based on drug use history before the symptomatic period, physical examination upon admission, and the presence of acute hepatitis as ascertained 
by laboratory investigations or histological findings. Experienced gastroenterologists in the field of toxic hepatitis indicated suspected DILI cases and excluded other possible causes of hepatitis such as hepatitis A, B, C, and E viruses, Epstein-Barr virus, cytomegalovirus, herpes simplex virus, autoimmune hepatitis, Wilson's disease, and alcohol. A total of 43 cases of $P$. multiflorum (herbs and pharmaceuticals)-induced liver injury were included in this study according to the diagnostic criteria for DILI. Another 43 healthy volunteers were chosen as controls. All participants provided written informed consent and the study protocol was approved by the ethical review committee.

\section{CYP1A2 genotyping}

For DNA extraction, genomic DNA was isolated from the peripheral blood of each subject using Ezup Column Blood Genomic DNA Isolation Kits (Shanghai, Hanbo Industry Co., Ltd.; Shanghai, China).

For polymerase chain reaction (PCR) amplification and DNA sequencing, the -3860 $\mathrm{G}>\mathrm{A}(C Y P 1 A 2 * 1 \mathrm{C}),-163 \mathrm{C}>\mathrm{A}(C Y P 1 A 2 * 1 \mathrm{~F}), C Y P 1 A 2 * 2, C Y P 1 A 2 * 7, C Y P 1 A 2 * 9$, and CYP1A2*11 alleles were detected by reverse transcription (RT)-PCR amplification using the primer pairs shown in Table 1 followed by DNA sequencing. The Chromas software (version 2.3) was used to analyze single-nucleotide polymorphisms (SNPs) of CYP1A2.

\begin{tabular}{|c|c|c|}
\hline Polymorphisms in CYP1A2 & Primers & Length of PCR products (bp) \\
\hline$-3860 \mathrm{G}>\mathrm{A}$ CYP $1 A 2 * 1 \mathrm{C}$ & $\begin{array}{l}\text { F: 5'-GCTACACATGATCGAGCTATAC-3' } \\
\text { R: 5'-CAGGTCTCTTCACTGTAATGTA-3' }\end{array}$ & 598 \\
\hline$-163 \mathrm{C}>\mathrm{A} C Y P 1 A 2 * 1 \mathrm{~F}$ & $\begin{array}{l}\text { F: 5'-CCCAGAAGTGGAAACTGAGA-3' } \\
\text { R: 5'-GGGTTGAGATGGAGACATTC-3' }\end{array}$ & 242 \\
\hline $63 \mathrm{C}>\mathrm{G} C Y P 1 A 2 * 2$ & $\begin{array}{l}\text { F: 5'-ATGAATGAATGAATGTCTC-3' } \\
\text { R: 5'-CTCTGGTGGACTTTTCAG-3' }\end{array}$ & 201 \\
\hline $3533 \mathrm{G}>\mathrm{A} C Y P 1 A 2 * 7$ & $\begin{array}{l}\text { F: 5'-CCTCCTCAGCACAACAAG-3' } \\
\text { R: 5'-CTAGCAGGGACAAACAGC-3' }\end{array}$ & 166 \\
\hline $248 \mathrm{C}>\mathrm{T}$ CYP $1 A 2 * 9$ & $\begin{array}{l}\text { F: 5'-GTATTCTGGGTGCTCAAGG-3' } \\
\text { R: 5'-GGTGGAGGTGTAGAGGTCA-3' }\end{array}$ & 276 \\
\hline $558 \mathrm{C}>\mathrm{A} C Y P 1 A 2 * 11$ & $\begin{array}{l}\text { F: 5'-ACCTTCTCCATCGCCTCT3' } \\
\text { R: 5'-AGCATCTCATCGCTACTCT-3' }\end{array}$ & 215 \\
\hline
\end{tabular}

\section{Statistical analysis}

Genotype and allelic frequencies of polymorphisms at each site were determined. The chi-square test was used to assess differences in the distribution of polymorphisms at each site between patients and controls.

\section{RESULTS}

\section{Clinical characteristics of the cases}

Forty-three cases of $P$. multiflorum-induced liver injury were recruited, accounting for $12.1 \%$ of 355 cases of DILI induced by TCM. These cases were also evaluated using the Maria 
criteria scale. The following results were obtained: scores in 8 cases were $>17,26$ cases were 14-17, and 9 cases were 10-13. Forty-one cases of patients were recovered after treatment, except for 2 cases, which were automatically discharged (Table 2).

Table 2. Characteristics of patients included in the study.

\begin{tabular}{lcccc}
\hline & Male/female & Age (years) & Length of hospitalization (days) & Maria scale (degree) \\
\hline $\begin{array}{l}\text { Polygonum multiflorum-induced DILI } \\
\text { 14-17:26 }\end{array}$ & $20 / 23$ & $46.1 \pm 10.2$ & $21.7 \pm 10.7$ & $>17: 8$ \\
$\begin{array}{l}\text { 10-13:9 } \\
\text { Control }\end{array}$ & $21 / 22$ & $48.2 \pm 10.5$ & ND & ND \\
\hline
\end{tabular}

\section{CYP1A2 genotyping}

CYP1A2 alleles were detected by RT-PCR and confirmed by gel electrophoresis (Figure 1). The Chromas software was used to analyze SNPs of CYP1A2 (a representative result for $C Y P 1 A 2 * 1 \mathrm{C}$ is shown in Figure 2).

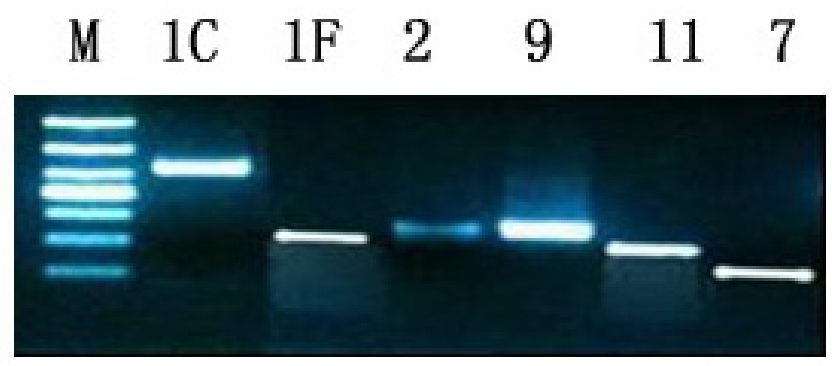

Figure 1. Gel electrophoresis results for $C Y P 1 A 2$ allele.

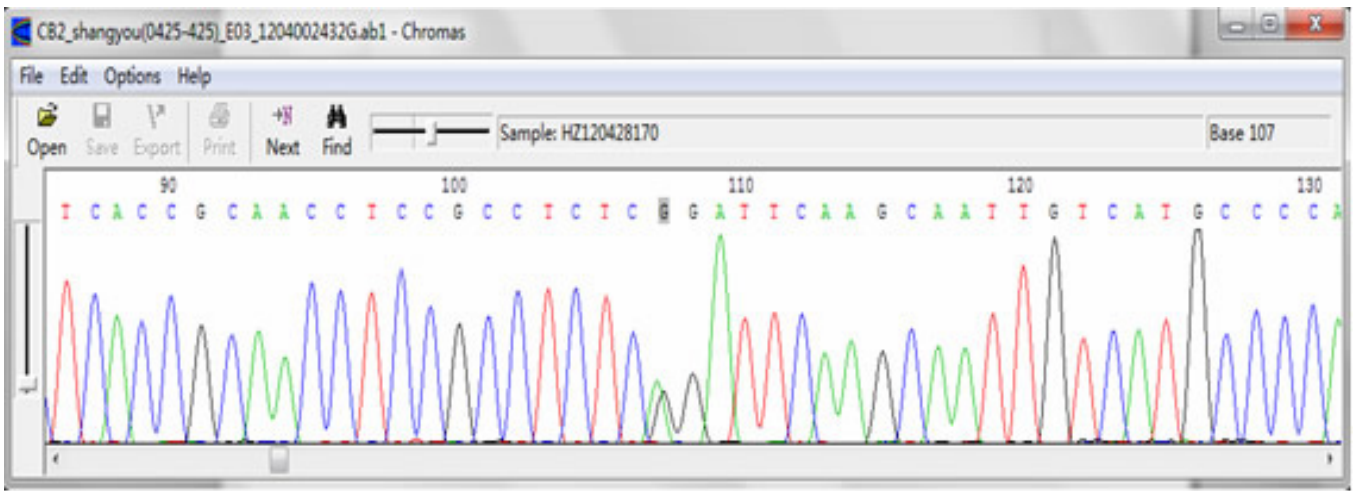

Figure 2. Gene sequence diagram of $-3860 \mathrm{G}>\mathrm{A} C Y P 1 A 2 * 1 \mathrm{C}(\mathrm{G} / \mathrm{A})$. 


\section{Distribution of each genotype and allele frequency differences in DILI patients and controls}

The distribution of genotype and allelic frequencies in DILI patients and controls are summarized in Table 3. The results revealed an association between the $\mathrm{G}>\mathrm{A}$ allele at position -3860 in P. multiflorum-induced DILI patients (46.5 vs 27.9\%). The frequency of the CYP $1 A 2 * 1 \mathrm{~F}$ allele was $63.9 \%$ in P. multiflorum-induced DILI patients, compared to $57.0 \%$ in healthy controls; this difference was not statistically significant. The allelic frequencies of CYP1A2*2, CYP1A2*7, CYP1A2*9, and CYP1A2*11 were too low to be detected.

\begin{tabular}{|c|c|c|c|c|}
\hline \multirow{2}{*}{$\begin{array}{l}\text { Polymorphism }(\mathrm{N}=43) \\
\text { CYP1A2*1C }\end{array}$} & \multicolumn{3}{|c|}{ Genotypes (\%) } & \multirow[t]{2}{*}{ Allele frequency } \\
\hline & $\mathrm{G} / \mathrm{G}$ & $\mathrm{G} / \mathrm{A}$ & $\mathrm{A} / \mathrm{A}$ & \\
\hline DILI patients & $11(25.6 \%)$ & $24(55.8 \%)$ & $8(18.6 \%)$ & $\mathrm{A}=46.5 \%$ \\
\hline Healthy controls & $23(51.2 \%)$ & $16(37.2 \%)$ & $4(9.3 \%)$ & $\mathrm{A}=27.9 \%$ \\
\hline CYP1A2*1F & $\mathrm{C} / \mathrm{C}$ & $\mathrm{C} / \mathrm{A}$ & $\mathrm{A} / \mathrm{A}$ & \\
\hline DILI patients & $11.6 \%$ & $48.8 \%$ & $39.5 \%$ & $\mathrm{~A}=63.9 \%$ \\
\hline Healthy controls & $20.9 \%$ & $44.2 \%$ & $34.9 \%$ & $\mathrm{~A}=57.0 \%$ \\
\hline CYP1A2*2 & $\mathrm{C} / \mathrm{C}$ & $\mathrm{C} / \mathrm{G}$ & $\mathrm{G} / \mathrm{G}$ & \\
\hline DILI patients & $100 \%$ & $0 \%$ & $0 \%$ & $\mathrm{G}=0 \%$ \\
\hline Healthy controls & $100 \%$ & $0 \%$ & $0 \%$ & $\mathrm{G}=0 \%$ \\
\hline CYP1A2*7 & $\mathrm{G} / \mathrm{G}$ & $\mathrm{G} / \mathrm{A}$ & $\mathrm{A} / \mathrm{A}$ & \\
\hline DILI patients & $100 \%$ & $0 \%$ & $0 \%$ & $\mathrm{~A}=0 \%$ \\
\hline Healthy controls & $100 \%$ & $0 \%$ & $0 \%$ & $\mathrm{~A}=0 \%$ \\
\hline CYP1A2*9 & $\mathrm{C} / \mathrm{C}$ & $\mathrm{C} / \mathrm{T}$ & $\mathrm{T} / \mathrm{T}$ & \\
\hline DILI patients & $100 \%$ & $0 \%$ & $0 \%$ & $\mathrm{~T}=0 \%$ \\
\hline Healthy controls & $100 \%$ & $0 \%$ & $0 \%$ & $\mathrm{~T}=0 \%$ \\
\hline CYP1A2*11 & $\mathrm{C} / \mathrm{C}$ & $\mathrm{C} / \mathrm{A}$ & $\mathrm{A} / \mathrm{A}$ & \\
\hline DILI patients & $100 \%$ & $0 \%$ & $0 \%$ & $\mathrm{~A}=0 \%$ \\
\hline Healthy controls & $100 \%$ & $0 \%$ & $0 \%$ & $\mathrm{~A}=0 \%$ \\
\hline
\end{tabular}

DILI $=$ drug-induced liver injury. ${ }^{\text {a }}<0.05$ (Chi-square test).

\section{DISCUSSION}

Complementary medicines including herbal preparations and nutritional supplements are widely used without prescriptions. Thus, there has been an increasing incidence of hepatotoxicity with the use of these agents (Ko, 2004).

Idiosyncratic liver toxicity caused by any drug is typically referred to as DILI. Most DILI involves reactions that appear to be unrelated to drug dose or concentration (Lucena et al., 2011). Although relatively rare, DILI is a serious clinical problem, with up to $10 \%$ of cases showing simultaneous severe elevations in alanine transaminase and bilirubin and development of liver failure. Metabolic idiosyncrasy is one of the main mechanisms of DILI, which is related to gene polymorphisms in metabolic enzymes. CYP450s are the main phase I drug metabolizing enzymes; genetic polymorphisms in CYP450 genes may mediate some cases of DILI (Deng et al., 2012).

SNPs have been identified that may result in variant CYP450 enzyme expression and/or activity (McGraw and Waller, 2012). In this study, we chose representative alleles of $C Y P 1 A 2$, among which $C Y P 1 A 2^{*} 1 \mathrm{~F}$ is reported to be associated with increased activity, 
while the $C Y P 1 A 2 * 1 \mathrm{C}, C Y P 1 A 2 * 2, C Y P 1 A 2 * 7$, and $C Y P 1 A 2 * 11$ variants are associated with decreased activity of the CYP1A2 gene (Zhou et al., 2009). The allelic frequency in the control group (ethnic Chinese) was similar to that reported in a study of ethnic Japanese subjects (Soyama et al., 2005). CYP1A2*1C and CYP1A2*1F showed allelic frequencies of 27.9 and $57.0 \%$, respectively $(\mathrm{N}=43)$ in our study, compared to 23.6 and $62.8 \%$, respectively, in the Japanese population. We did not detect mutations in $C Y P 1 A 2 * 2, C Y P 1 A 2 * 7, C Y P 1 A 2 * 9$, and $C Y P 1 A 2 * 11$ because these allelic frequencies were too low. These alleles are present at frequencies of $0.2-0.4 \%$ in the Japanese population (Soyama et al., 2005). Based on our results, there was no significant difference in the allelic frequencies of $C Y P 1 A 2 * 1 \mathrm{~F}, C Y P 1 A 2 * 2$, CYP1A2*7, and CYP1A2*11. However, the CYP1A2*1C frequency in P. multiflorum-induced DILI patients was $46.5 \%$, which was significantly higher compared to the frequency of $27.9 \%$ in healthy controls. Thus, subjects with the CYP1A2*1C mutation may have decreased activity of the CYP1A2 protein, thereby inhibiting the metabolism of $P$. multiflorum and causing accumulation of toxic substances.

In conclusion, mutations in CYP1A2*1C may cause $P$. multiflorum-induced liver injury. The incidence of $P$. multiflorum-induced liver injury is low, and this study included relatively few patients. Thus, further study into the mechanism of $P$. multiflorum-induced liver injury is necessary.

\section{ACKNOWLEDGMENTS}

The authors would like to thank Paul Getty from the University of Glasgow for providing useful comments and language editing, which have greatly improved the manuscript. Research supported by the Administration of Traditional Chinese Medicine Scientific Research Foundation of Zhejiang Province (\#2011ZA053) and the National Natural Science Foundation of China (\#81100277).

\section{REFERENCES}

Anonymous (2013). CYP1A2 allele nomenclature. Available at [http://www.cypalleles.ki.se/cyp1a2.htm]. Accessed September 5, 2013.

Cárdenas A, Restrepo JC, Sierra F and Correa G (2006). Acute hepatitis due to shen-min: a herbal product derived from Polygonum multiflorum. J. Clin. Gastroenterol. 40: 629-632.

Deng R, Yang T, Wang Y and Tang N (2012). CYP2E1 RsaI/PstI polymorphism and risk of anti-tuberculosis druginduced liver injury: a meta-analysis. Int. J. Tuberc. Lung Dis. 16: 1574-1581.

Empey PE (2010). Genetic predisposition to adverse drug reactions in the intensive care unit. Crit. Care Med. 38 : S106-S116.

Gervasini G, Garcia M, Macias RM, Cubero JJ, et al. (2012). Impact of genetic polymorphisms on tacrolimus pharmacokinetics and the clinical outcome of renal transplantation. Transpl. Int. 25: 471-480.

Jung KA, Min HJ, Yoo SS, Kim HJ, et al. (2011). Drug-induced liver injury: twenty five cases of acute hepatitis following ingestion of Polygonum multiflorum Thunb. Gut. Liver 5: 493-499.

Ko RJ (2004). A U.S. perspective on the adverse reactions from traditional Chinese medicines. J. Chin. Med. Assoc. 67: 109-116.

Lucena MI, Molokhia M, Shen Y, Urban TJ, et al. (2011). Susceptibility to amoxicillin-clavulanate-induced liver injury is influenced by multiple HLA class I and II alleles. Gastroenterology 141: 338-347.

Mazzanti G, Battinelli L, Daniele C, Mastroianni CM, et al. (2004). New case of acute hepatitis following the consumption of Shou Wu Pian, a Chinese herbal product derived from Polygonum multiflorum. Ann. Intern. Med. 140: W30.

McGraw J and Waller D (2012). Cytochrome P450 variations in different ethnic populations. Expert Opin. Drug Metab. Toxicol. 8: 371-382. 
Panis B, Wong DR, Hooymans PM, De Smet PA, et al. (2005). Recurrent toxic hepatitis in a Caucasian girl related to the use of Shou-Wu-Pian, a Chinese herbal preparation. J. Pediatr. Gastroenterol. Nutr. 41: 256-258.

Polimanti R, Piacentini S, Manfellotto D and Fuciarelli M (2012). Human genetic variation of CYP450 superfamily: analysis of functional diversity in worldwide populations. Pharmacogenomics 13: 1951-1960.

Soyama A, Saito Y, Hanioka N, Maekawa K, et al. (2005). Single nucleotide polymorphisms and haplotypes of CYP1A2 in a Japanese population. Drug Metab. Pharmacokinet. 20: 24-33.

Uslu A, Ogus C, Ozdemir T, Bilgen T, et al. (2010). The effect of CYP1A2 gene polymorphisms on theophylline metabolism and chronic obstructive pulmonary disease in Turkish patients. BMB Rep. 43: 530-534.

Wong CC, Li HB, Cheng KW and Chen F (2006). A systematic survey of antioxidant activity of 30 Chinese medicinal plants using the ferric reducing antioxidant power assay. Food Chem. 97: 705-711.

Zhang RC, Liu B, Sun ZX and Xu DY (2010). Effects of extract of Polygonum multiflorum on cell cycle arrest and apoptosis of human liver cell line L02. Zhong Xi Yi Jie. He. Xue Bao 8: 554-561.

Zhou SF, Yang LP, Zhou ZW, Liu YH, et al. (2009). Insights into the substrate specificity, inhibitors, regulation, and polymorphisms and the clinical impact of human cytochrome P450 1A2. AAPS J. 11: 481-494. 